\title{
REMOTE SENSING BASED ASSESSMENT OF VARIATION OF SPATIAL DISPARITIES
}

\author{
József BENEDEK ${ }^{1}$, Kinga IVAN ${ }^{2}$
}

DOI: $10.21163 / G T \_2018.131 .01$

\begin{abstract}
:
The aim of this paper is to identify the relationship between the spatial and temporal variation of spatial disparities (measured with Gross Domestic Product, GDP) and nighttime lights at regional (county) level in Romania. The analysis presumed using night-time lights data captured by the DMSP-OLS satellites, in addition to official statistical data expressing economic income (GDP). The DMSP-OLS night-time lights data collected by the National Oceanic and Atmospheric Administration (NOAA) has a spatial resolution of $30 \mathrm{arc}$ second and is available for the period of 1992-2013. The delimitation of unlit and lit areas was performed using ArcGIS software. The lower value of light intensity reflects less developed areas and those with higher value reflects more developed areas. The assessment relationship between GDP and night lights value was made using statistical correlation. The results show a strong linear correlation between the GDP and night lights value. It means that night-time lights are an excellent proxy for measuring spatial (regional) disparities. Moreover, based on the linear dependence and the spatial relation between these two datasets, we will be able in the future to go one step further and measure the level of spatial disparities at local level (cities and communes), where official statistical data is not recorded.
\end{abstract}

Key-words: Night-time light, Spatial disparities, DMSP-OLS satellite images, Romania.

\section{INTRODUCTION}

Remote sensing offers a wide range of satellite imagery which is widely used in various fields such as geography, environmental studies, spatial planning, topography or economics. Depending on the time when these images were taken we distinguish satellite images captured during the day and satellite images captured at night. Lately more and more attention has been paid to the use of satellite images captured at night in order to determine socio-economic data corresponding to micro scale spatial units, where official statistical data is not available. Night-time lights (NTL) resulting from the illumination of public and private spaces, roads or from the use of vehicles during night, reflects the intensity of human economic activity of an area (Chen \& Nordhaus, 2011; Henderson et al., 2012; Mellander et al., 2015; Pinkovskiy \& Sala-I-Martin, 2016). Information on the degree of night-time illumination of a spatial unit can be obtained on a global scale for a period of more than 20 years with the assistance of remote sensing. In this context, using remote sensing and Geographic Information System (GIS) may provide new perspectives for assessing economic performance at national and sub-national level. Satellite images also offer a great potential for the spatial and temporal analysis of the degree of night-time illumination of a spatial unit. Night-time lights (NTL) data captured by the satellites in order to estimate economic growth is a topical one, being used lately in numerous studies.

\footnotetext{
${ }^{1}$ University of Miskolc, Institute of World and Regional Economics, 3515 Miskolc, Hungary, jozsef.benedek@ubbcluj.ro;

${ }^{2}$ Babeş-Bolyai University, 400006 Cluj-Napoca, Romania, kinga.ivan@ubbcluj.ro.
} 
Elvidge et al. (1997) have conducted research on the relationship between illuminated areas and GDP for 21 countries, obtaining a very strong correlation between the two analyzed variables. Henderson et al. (2012) has used night-time lights data to measure the real income growth, and Henderson et al. (2011) analyzed the relation between night-time lights and GDP, having also obtained a very strong correlation.

Night-time lights data have been used by Villa (2016) in assessing the effects of social transfers on the economic growth at local level. The study revealed that social transfers have generated positive effects on economic growth in Columbia. Ghosh et al. (2013) have used satellite images captured at night to measure human welfare. In another approach Jean et al. (2016) have used high resolution satellite images captured during the day to make predictions about the spatial distribution of economic well-being in five countries in Africa. In other studies the decoupling between the energy consumption and economic growth was examined (Szlávik and Sebestyén Szép, 2017).

In the present paper we proposed to analyze the relation between the night-time lights variation and economic spatial disparities at national and sub-national level in Romania for the period 2000-2013. Thus we have followed the temporal variation analysis of night-time lights (NTL) at national and sub-national level in Romania, respectively the relationship between the mean of night-time light (NTL) value and Gross Domestic Product (GDP). Similar concerns had Iuga (2015) who having analyzed the link between the evolution of climate change and socio-economic development in Romania, using as key indicator the real Gross domestic product (GDP) per capita. The scientific and practical relevance of our study is related to the major bottlenecks in measuring spatial disparities and economic development in Romania: 1. GDP is directly measured only at national level, the regional GDP being calculated indirectly with two years average delay from the national GDP calculations; 2. there is no statistical record of GDP on the local level (cities and communes). The practical relevance of this issue is given by the fact that GDP is used as main indicator for the designation of areas eligible for European or national development support schemes.

\section{STUDY AREA AND DATA}

Romania is situated in the south-eastern part of Europe, its territory comprises 238391 $\mathrm{km}^{2}$ and its population reached 19760314 inhabitants in 2016 (Eurostat Database, 2017).

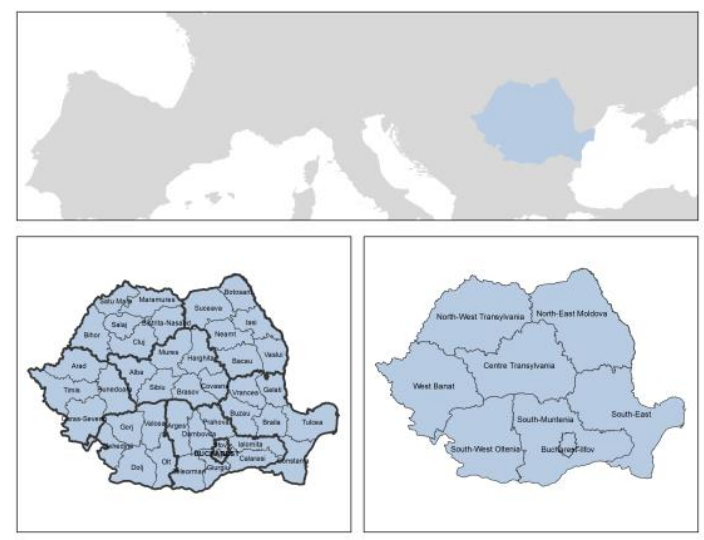

Fig. 1. Romanian counties (left) and development regions (right) (Source: authors). 
The country is organized in 41 administrative counties (judete in Romanian) and Bucharest municipality (Fig. 1). The counties (NUTS-3 units) are grouped in 8 development regions (NUTS-2 level): North-West Transylvania, North-East Moldova, Center Transylvania, West Banat, South-West Oltenia, South-Muntenia, Bucharest-Ilfov, South-East (Black Sea) (Fig. 1). Both sub-national levels (NUTS-2 and 3) are the basic territorial units for the distribution of EU and national founded development policies.

Remote sensing provides data of global scale on artificial illumination during the night. A dataset that proved to be very useful and has been used in many studies, is DMSP-OLS night-time lights data (Fig. 2) collected and offered by the National Oceanic and Atmospheric Administration (NOAA). These data have a spatial resolution of 30 arc second $\left(1 \mathrm{~km}^{2}\right)$ and can be obtained free of charge from the NOAA database for the period 19922013 (NOAA, 2017).
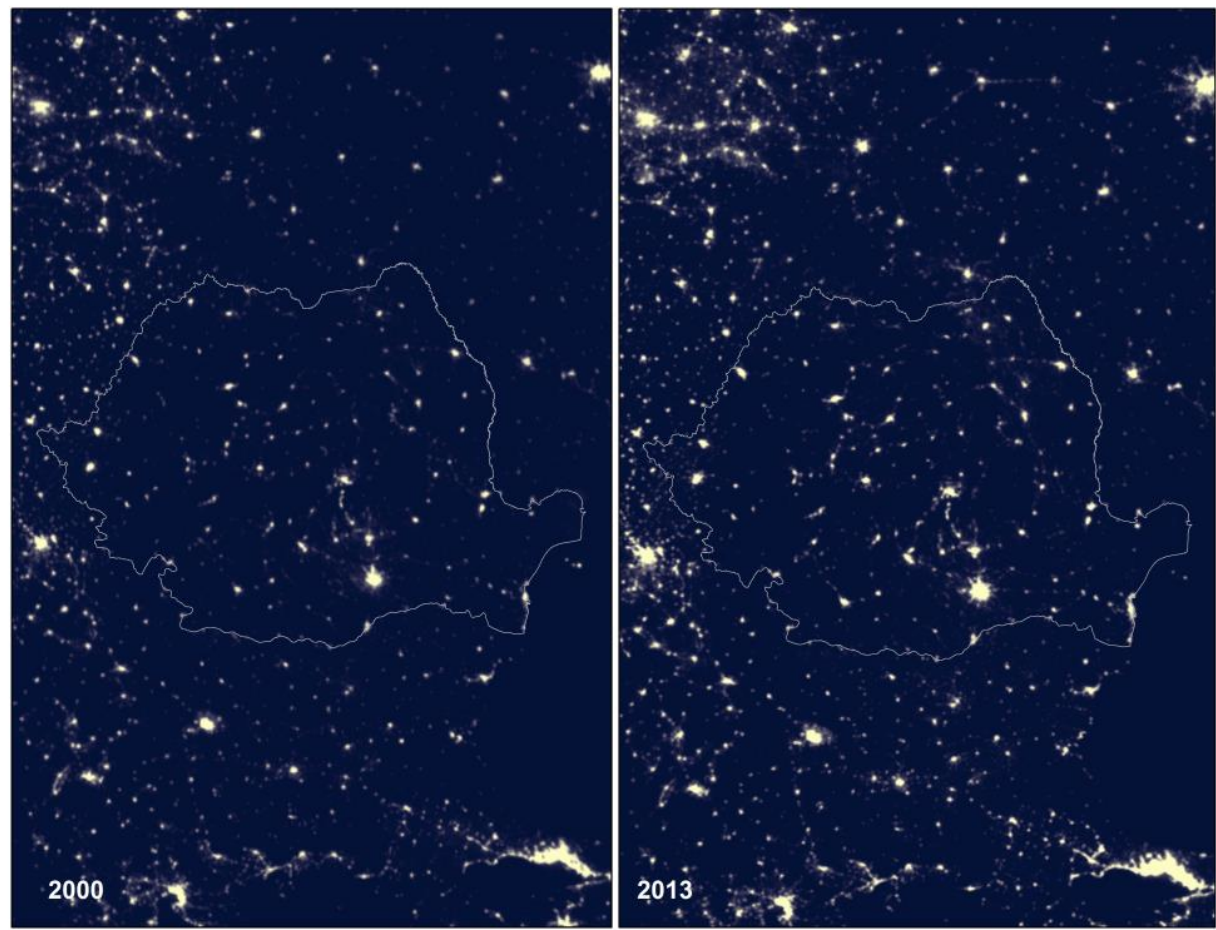

Fig. 2. DMSP-OLS night-time lights in Romania between 2000 and 2013 (Source of data: NOAA, 2017).

DMSP - OLS satellites orbit Earth and record light intensity with the help of the OLS sensors in every location on Earth from 20:30 until 22:00 local time, between $65^{\circ}$ north latitude and $65^{\circ}$ south latitude (Villa, 2016). The intensity of night-time lights reflects light both inside and outside their premises (Henderson et al., 2012). The main indicator of both spatial economic disparities and economic output is the Gross Domestic Product (GDP), more exactly the Gross Domestic Product relative to the total population of the considered area (GDP per capita). The values of GDP at national and sub-national level have been extracted for the period 2000-2013 from the Eurostat Database (Eurostat Database, 2017). 


\section{METHODOLOGY}

\subsection{Evaluation of temporal variation of night-time illumination}

The GIS (Geographic Information System) tool has been used to extract the night-time illumination data at national and sub-national level in Romania. DMSP (Defense Meteorological Satellite Program) satellite imagery purchased from the National Oceanic and Atmospheric Administration database (NOAA, 2017), a total number of 14 images (from 2000 to 2013), have been processed in ArcGIS 10.4, which allowed us to delimit the unlit and lit areas.

The value of light intensity measured by the DMSP-OLS satellites is ranging from 063 Digital Number. 0 values correspond to unlit areas, and those with 63 to high lit areas. From the illuminated areas those with a lower value of the light intensity reflect less developed areas, and those with a higher value reflect the more developed ones. In order to group areas depending on the light intensity value first we removed the unlit areas, those with 0 value. Thus in the first phase unlit areas have been eliminated for each reference year and illuminated areas have been delimited. This process has been carried out with the assistance of Set Null function of ArcGIS 10.4, in which zero values were assigned to all $\mathrm{DN} \leq 0$ values. Subsequently with the assistance of Zonal Statistics function, the mean night-time value was calculated, then the surface of illuminated areas at national, regional and county level for each reference year (Fig. 3).

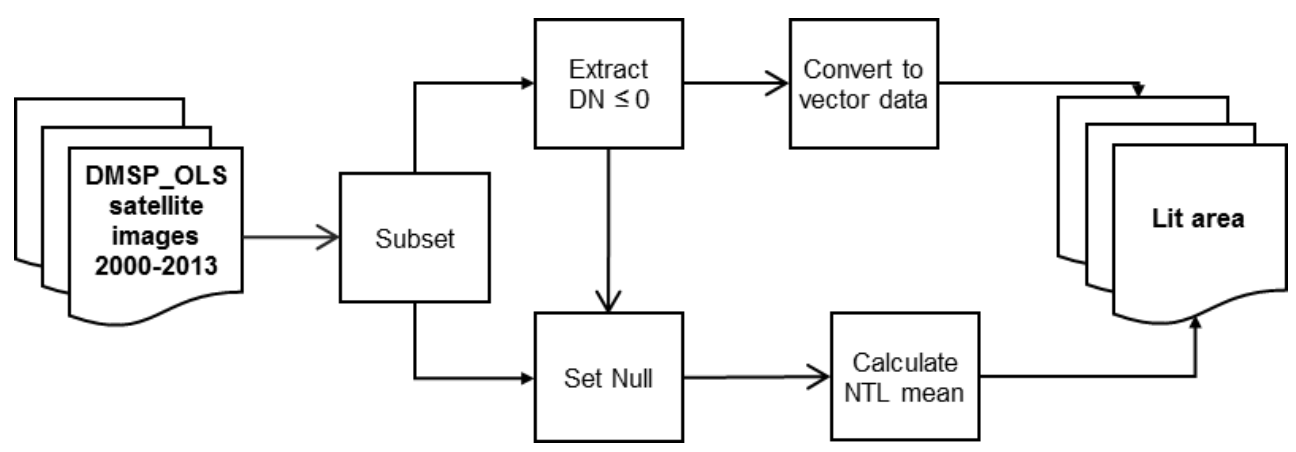

Fig. 3. Flowchart of extracting lit areas.

Values thus obtained were matched with the statistical data corresponding to the analyzed spatial units. Then using the data on the total illuminated area corresponding to each reference year, the growth rate of night-time light (NTL) has been calculated as follow:

$$
N T L_{\text {rate }}=\frac{\left(N T L_{1}-N T L_{o}\right)}{N T L_{o}} \times 100
$$

Where,

$\mathrm{NTL}_{1}$ - represents night-time light area from the following year;

$\mathrm{NTL}_{0}$ - represents night-time light area from the previous year;

\subsection{Analysis of the relationship between mean of night-time light value and GDP}

According to Henderson et al. (2012) lights in an area reflect the total intensity of income. In order to evaluate the link between economic output in Romania and night-time 
illumination we used a statistical correlation. The GDP (and GDP per capita) is the classic indicator that dominates the methodology of measuring the level of the development at national and regional level (Pinkovskiy \& Sala-I-Martin, 2016) and it is an important variable in analyzing economic growth (Henderson et al., 2012) and spatial disparities. In the research of the relation between luminosity and GDP, in some studies the sum of light intensity values were computed (Villa, 2016; Ghosh et al., 2013) while in other studies the mean of night light value (Mellander et al., 2015) or the lit area were used (Elvidge et al., 1997; Ebener et al., 2015). According to Mellander et al. (2015) in the present research we used the mean of night-time light (NTL) value.

The intensity of linear relationship between the mean of night-time light value and GDP was determined using by Pearson correlation coefficient ( $r$ ). The Pearson correlation coefficient (r) of two variables, $x_{i}$ and $y_{i}$, was calculated on the basis of the following equation (Lee \& Wong, 2001):

$$
r=\frac{\frac{\sum_{i=1}^{n} x i y i}{n}-\bar{X} \bullet \bar{Y}}{S x S y}
$$

where, $\bar{X}$ and $\bar{Y}$ represent the mean of $\mathrm{x}$ and $\mathrm{y}$, and $S_{x}$ and $S_{y}$ represent standard deviation of $\mathrm{x}$ and $\mathrm{y}$, calculated with the formulas:

$$
S x=\sqrt{\frac{\sum_{n=1}^{n} x^{2}}{n}}-\bar{X}^{2} S y=\sqrt{\frac{\sum_{n=1}^{n} y^{2}}{n}}-\bar{Y}^{2}
$$

\section{RESULTS AND DISCUSSIONS}

The graphical representation showing the variation of illuminated areas and GDP (Gross Domestic Product at current market prices) in Romania for the period 2000-2013 illustrates that the these two variables have similar trends, excepting the year of 2013, when the illuminated areas decrease. The decline of the illuminated area is explained by the population decline in the year of 2013 (Fig. 4).

It can be noted that with the increase or decrease of the GDP, the illuminated areas in Romania follow the same trend. This trend is supported by the statistical results obtained by analyzing the relationship between mean of night-time light value and GDP on national level, where the calculated Pearson correlation coefficient was 0.70 , which fact indicates a strong link between these two variables.

This means that night-time light can be used as proxy for economic output and spatial economic disparities in Romania. In addition, its growth trend reflects well the trend of economic growth and development. 


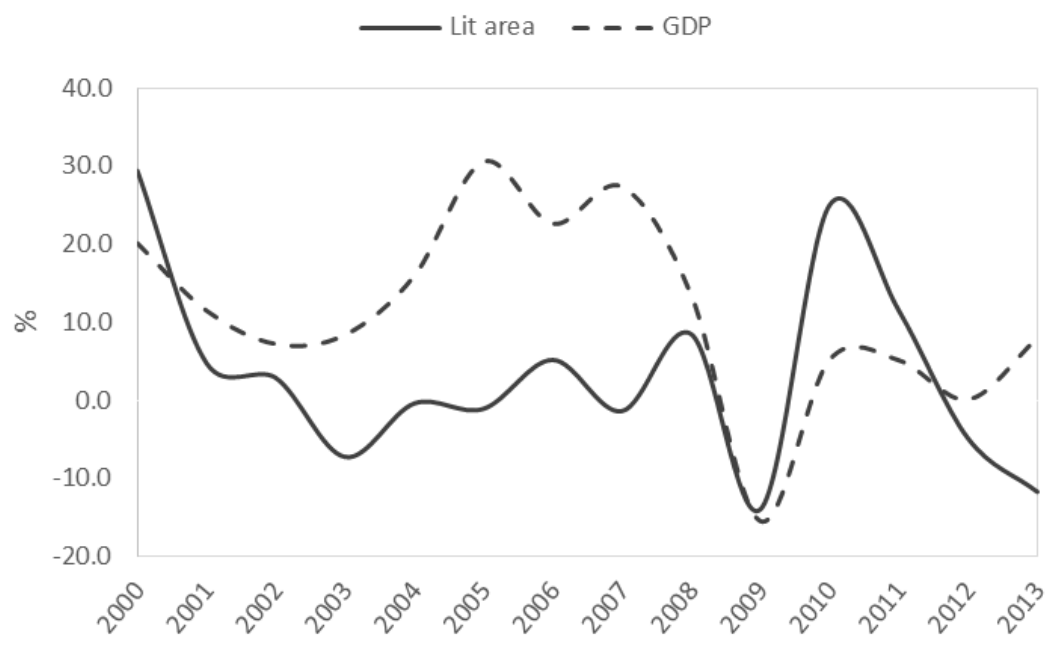

Fig. 4. Development rate (in \%) of illuminated areas and of the GDP in Romania in the period $2000-2013$.

On regional level the degree of correlation between the mean of night-time light and GDP in the period 2000-2013 was very high in Bucharest-Ilfov Region. The statistical analysis has identified three clusters within the distribution: the first one corresponding with the period between 2000-2002 ( $\mathrm{r}=0.83$ ), the second one between 2003-2009 ( $\mathrm{r}=0.94)$ and the third one between 2010-2013 ( $\mathrm{r}=-0.78$ ) (Fig. 5a). The fifth-order polynomial dynamics from Fig. 5b $\left(\mathrm{R}^{2}=0.86\right)$ adjusts much better to the cloud of points than the simple linear regression from Fig. 5a. This overall curve highlights more precisely the influence of GDP on night-time light, namely the dynamics of well-being in Romania.

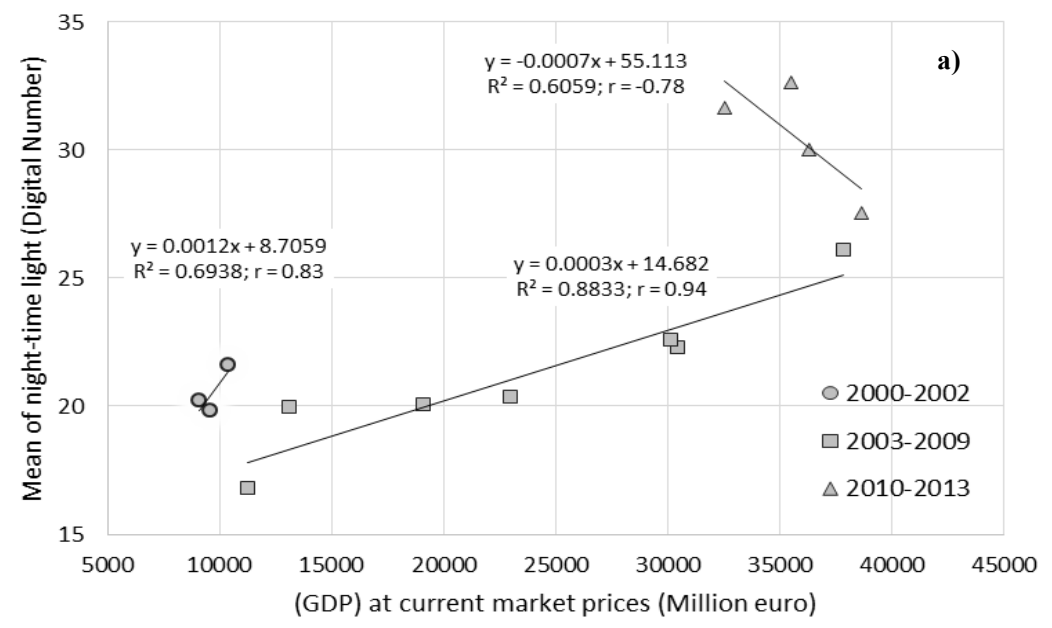




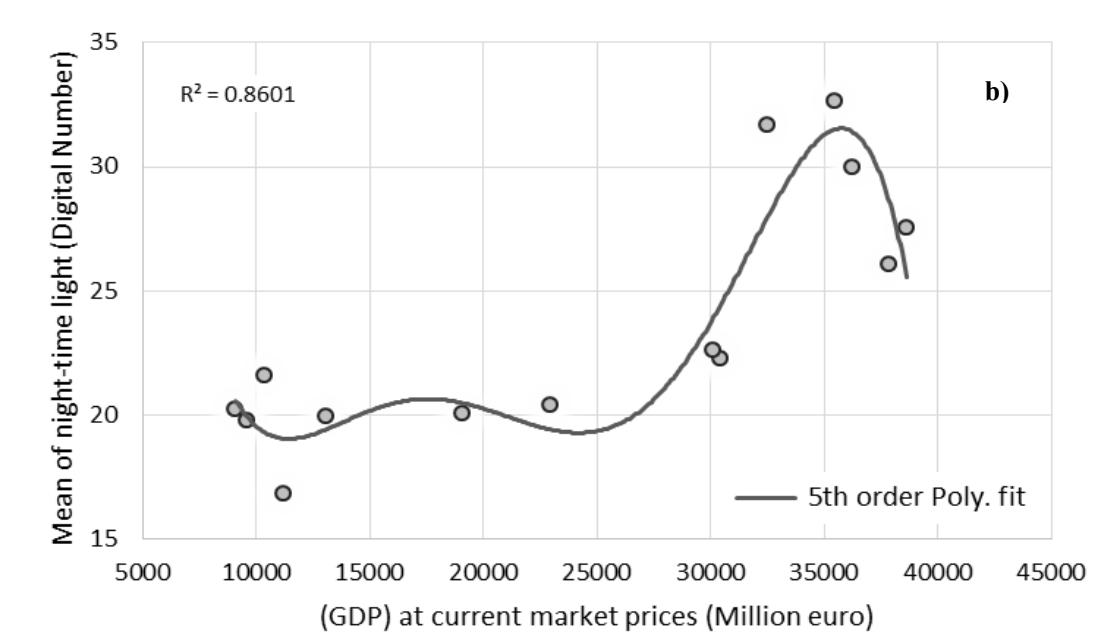

Fig. 5. Graph correlating illumination and GDP, in Bucharest- Ilfov Region (2000-2013).

For other development regions, the results showed a similar high statistical link for three of them: West Banat Region ( $r=0.75)$, South-East Region $(r=0.71)$, North-West Transylvania Region $(\mathrm{r}=0.70)$, and slightly lower relation in the case of the rest of four regions: North-East Moldova Region ( $\mathrm{r}=0.55)$, South-Muntenia Region ( $\mathrm{r}=0.64)$, Centre Transylvania Region ( $\mathrm{r}=0.68)$ and South-West Oltenia Region $(\mathrm{r}=0.69)$.

Based on these results we can state that, on national and regional level, the variation of illumination largely reflects the intensity of economic activity in Romania. Therefore, the night-time illumination can be used as an alternative proxy to the GDP for the measurement of economic and social development.

On county level, following the analysis of the degree of dependence between the mean of night-time light and GDP (Table 1), we have distinguished four categories of counties: a) economic activity was very highly reflected by illumination, $\mathrm{r} \geq 0.80$; $\mathrm{b}$ ) economic activity was highly reflected by illumination $r<0.80$ and $r \geq 0.65$; c) economic activity was medium-level reflected by illumination $r<0.65$ and $r \geq 0.50$; d) economic activity was lowly reflected by illumination $r<0.50$ (Fig. 6).

As a general observation, we can see from Fig. 6 and Table 1 that for the large number of cases the correlation between night-time illumination and GDP was strong.

We have few exemptions, with low correlation, where further research is needed. Our main hypothesis for these cases is that their official GDP is underestimated. The counties in this category $(\mathrm{r}<0.5)$ have low levels of GDP and are characterized by a strong outmigration (Benedek \& Török, 2014; Benedek, 2015).

The correlation increases in the case of counties with higher values of GDP and less outmigration. Future research is needed to fully understand and to clarify these spatial differences on county levels. That means in the same time, that the use of night-lights as proxy for GDP at county level faces some limitations. 
Table 1.

The degree of dependence between GDP and mean of night-time light value.

\begin{tabular}{|l|c|l|c|}
\hline \multicolumn{5}{|c|}{ GDP vs. night-time light (2000-2013) } \\
\hline \multicolumn{1}{|c|}{ Sub-regions } & Pearson (r) & \multicolumn{1}{c|}{ Sub-regions } & Pearson (r) \\
\hline Bihor & 0.84 & Galati & 0.60 \\
\hline Bistrita-Nasaud & 0.51 & Tulcea & 0.63 \\
\hline Cluj & 0.69 & Vrancea & 0.62 \\
\hline Maramures & 0.51 & Arges & 0.58 \\
\hline Satu Mare & 0.58 & Calarasi & 0.84 \\
\hline Salaj & 0.59 & Dambovita & 0.65 \\
\hline Alba & 0.69 & Giurgiu & 0.81 \\
\hline Brasov & 0.75 & Ialomita & 0.68 \\
\hline Covasna & 0.40 & Prahova & 0.56 \\
\hline Harghita & 0.48 & Teleorman & 0.64 \\
\hline Mures & 0.61 & Bucuresti & 0.74 \\
\hline Sibiu & 0.80 & Ilfov & 0.79 \\
\hline Bacau & 0.42 & Dolj & 0.78 \\
\hline Botosani & 0.54 & Gorj & 0.74 \\
\hline Iasi & 0.59 & Mehedinti & 0.22 \\
\hline Neamt & 0.58 & Olt & 0.57 \\
\hline Suceava & 0.61 & Valcea & 0.40 \\
\hline Vaslui & 0.14 & Arad & 0.86 \\
\hline Braila & 0.44 & Caras-Severin & 0.38 \\
\hline Buzau & 0.63 & Hunedoara & 0.65 \\
\hline Constanta & 0.81 & Timis & 0.80 \\
\hline & & & \\
\hline
\end{tabular}

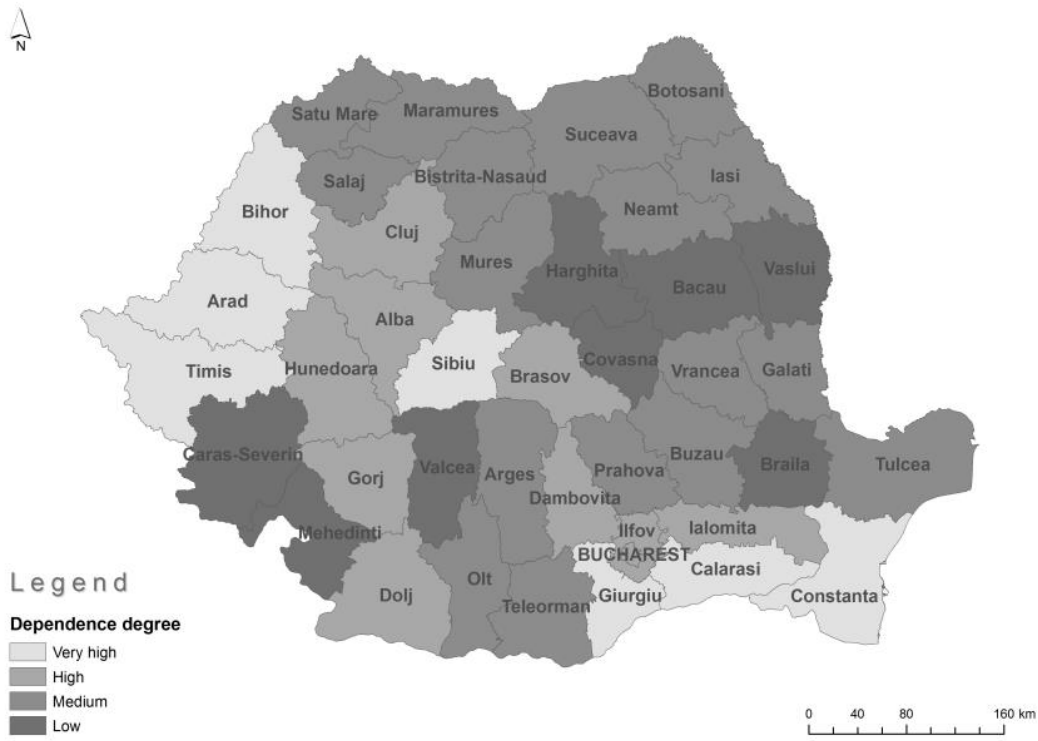

Fig. 6. Illustration of the degree of dependence between mean of night-time light and GDP at county level. 


\section{CONCLUSIONS}

Night-time lights data obtained by remote sensing proved to be useful in analyzing the lit area variation as well as in assessing the economic output differences on national and sub-national level in Romania. The study of the relationship between GDP and mean of night-time light value revealed a direct relationship between the two variables, both on national, regional and county level. These results demonstrate that night-time illumination reflects well the intensity of economic activity in Romania. Therefore, it can be used with confidence in estimating economic output differences and economic growth in Romania at national and regional level. However, its use at county level needs further investigations.

\section{R E F E R E N C E S}

Benedek, J. \& Török, I. (2014) County-level demographic disparities in Romania. Transylvanian Review, 23 (2), 138-147.

Benedek, J. (2015) Spatial differentiation and core-periphery structures in Romania. Eastern Journal of European Studies, 6 (1), 49-61.

Chen, X. \& Nordhaus, W. D. (2011) Using luminosity data as a proxy for economic statistics. Proceedings of the National Academy of Sciences, 108 (21), 8589-8594.

Ebener, S., Murray, C., Tandon, A. \& Elvidge, C. C. (2005) From wealth to health: Modelling the distribution of income per capita at the sub-national level using night-time light imagery. Int $J$ Health Geogr, 4 (5), 1-17.

Elvidge, C. D., Baugh, K. E., Kihn, E. A., Kroehl, H. W. \& Davis, E. R. (1997) Mapping city lights with night-time data from the DMSP operational linescan system. Photogrammetric Engineering \& Remote Sensing, 63 (6), 727-734.

EUROSTAT DATABASE (2017). - Available from: http://ec.europa.eu/eurostat/.[Accessed March 2017].

Ghosh, T., Anderson, S. J., Elvidge, C. D. \& Sutton, P. C. (2013) Using nighttime satellite imagery as a proxy measure of human well-being. Sustainability, 5, 4988-5019.

Henderson, V., Storeygard, A. \& Weil, D. N. (2011) A Bright Idea for Measuring Economic Growth. American Economic Review: Papers \& Proceedings, 101 (3), 194-99.

Henderson, V., Storeygard, A. \& Weil, D. N. (2012) Measuring economic growth from outer space. American Economic Review, 102 (2), 994-1028.

Iuga, C. (2015) Socioeconomic Development and Climate Change - Basic Components of Sustainable Development in European Union Countries. Journal of Environmental Protection and Ecology, 16 (3), 1168-1178.

Jean, N., Burke, M., Xie, M., Davis, W. M., Lobell, D. B. \& Ermon, S. (2016) Combining satellite imagery and machine learning to predict poverty. Science, 353 (6301), 790-794.

Lee, J. \& Wong, D.W.S.(2001) Statistical Analysis with ArcView GIS, John Wiley and Sons, New York.

Mellander, C., Lobo, J., Stolarick, K. \& Matheson, Z. (2015) Night-Time Light Data: A Good Proxy Measure for Economic Activity? PLoS ONE, 10 (10), 1-18.

NOAA (2017). - National Oceanic and Atmospheric Administration. Available from: https://ngdc.noaa.gov/eog/ [Accessed January 2017].

Pinkovskiy, M. \& Sala-I-Martin, X. (2016) Lights, camera,... income! Illuminating the national accounts-household surveys debate. Quarterly Journal of Economics, 131 (2), 579-631.

Szlávik, J. \& Sebestyén Szép, T. (2017) Delinking of energy consumption and economic growth in the visegrad group. Geographia Technica, 12 (2), 139-149.

Villa, J. M. (2016) Social Transfers and Growth: Evidence from Luminosity Data. Economic Development and Cultural Change, 65 (1), 39-61. 